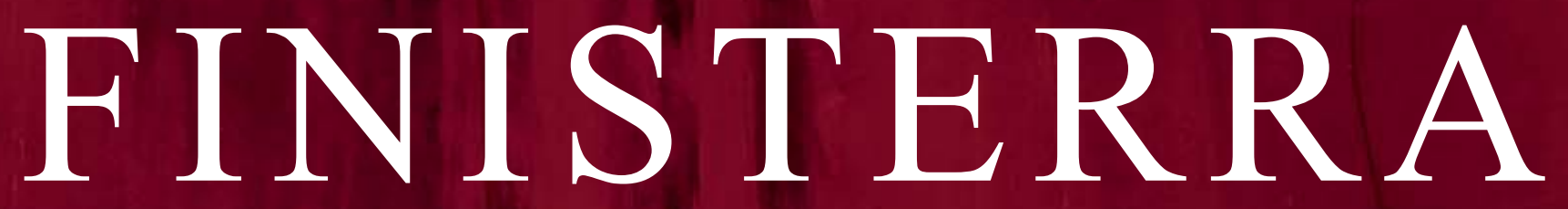

Revista Portuguesa de Geografia

Centro

de Estudos

Geográficos

Volume LII

Número 106

Dezembro 2017 


\title{
GOVERNANÇA COMO MODELO DE GESTÃO DOS TERRITÓRIOS: UM OLHAR SOBRE O DOURO VINHATEIRO
}

\author{
Rita AlcÂntara ${ }^{1}$
}

RESUMO - A Região Demarcada do Douro, em Portugal, é considerada uma das mais antigas do mundo na regulamentação da actividade vitivinícola. O objetivo deste artigo é analisar a Região do Douro na perspectiva da governança e dos agentes e a (des)articulação de poderes que organizam o espaço. No marco teórico, aprofunda-se o entendimento sobre governança e se estabelece diálogo com a abordagem institucionalista, por meio das políticas públicas portuguesas específicas para o setor, mediante o suporte de levantamentos bibliográficos, entrevistas e pesquisas de campo. Conclui-se que, no processo de gestão do Douro produtor de vinhos, o modelo de governança não ocorre em sua plenitude, uma vez que dele participam apenas dois atores: o Estado e o setor privado.

Palavras-chave: Governança; instituições; políticas públicas; economia do vinho; organização do espaço.

ABSTRACT - GOVERNANCE AS A MODEL OF TERRITORIAL MANAGEMENT: THE CASE OF THE DOURO WINE REGION. The demarcated wine-producing region of Douro, in Portugal, is considered to be one of the world's oldest in the business of wine regulation. The objective of this paper is to study how it is governed, its agents and the (dis) articulation of powers that organize the space. In theoretical terms, the nature of this governance is analysed from an institutionalist approach, through specific Portuguese public policies for the sector with the support of a literature review, interviews and field research. It concludes that the governance model of wine production in Douro is incomplete as it only involves two actors: the state and the private sector.

Keywords: Governance; institutions; public policy; economics of wine; organization of space.

1 Professora Associada do Departamento de História da Universidade Federal Rural de Pernambuco - Ufrpe, Rua Dom Manoel de Medeiros, s/n, Dois Irmãos, CEP 52171-900, Recife/PE, Brasil. E-mail: ritaalcantara@outlook.com 
RÉSUMÉ - LA GOUVERNANCE, EN TANT QUE MODĖLE DE GESTION TERRITORIALE: LE CAS DU VIGNOBLE DU DOURO. La Région classée du vignoble do Douro est considérée comme celle où le commerce du vin a été le plus anciennement réglementé au monde. On étudie ici la façon dont sa gouvernance, ses agents et la (des)articulation des pouvoirs y organisent l'espace. Au plan théorique, on analyse la nature de cette gouvernance, en abordant le problème institutionnel des politiques publiques portugaises relatives à ce secteur, grâce à des consultations bibliographiques, à des entrevues et au travail de terrain. En conclusion, la production du vin apparait gérée par une gouvernance incomplète, puisqu'elle ne comporte que deux acteurs : l'État et le secteur privé.

Mots clés: Gouvernance; institutions; politiques publiques; économie viticole; organisation de l'espace.

\section{INTRODUÇÃO}

É possível pensar o espaço através de vários prismas, como o econômico, o político, o social, etc. Em Portugal, existem várias regiões demarcadas onde se cultiva a vinha e se produz o vinho, dentre elas, a Alentejo, o Douro e a Estremadura. Todavia, há algo singular no "Douro e seu entorno", cuja paisagem foi construída pelo homem e organizada para a produção de vinhos, dentre eles, o do Porto.

O segmento é regulamentado a vários níveis, tais como a expansão da área, a quantidade a ser produzida e a renovação da vinha. Então, o que faz essa região diferente das outras?

A Região Demarcada do Douro (RDD) é a das mais antigas do mundo em termos de regulamentação do negócio do vinho. A realidade remete a uma lógica de produção controlada, com liberações de produção, expansão e renovação das vinhas previamente autorizadas. A estratégia é de uma produção estável, relativamente pequena, capaz de manter o preço elevado. Esses e outros aspectos levaram a região a adquirir uma grande notoriedade associada ao vinho fortificado, dito vinho do Porto.

A especificidade da região em termos de paisagem tornou-a Patrimônio da Humanidade, em dezembro de 2001. Em nosso entendimento, sua importância extrapola os limites de um acidente geográfico e de um bem público, para se converter numa matriz de possibilidades estratégicas, da qual depende, parcialmente o desenvolvimento de base territorial da região.

Além disso, a região do Douro, produtora de vinhos, é lugar de encontro de lógicas globais e locais, devido essencialmente à produção e ao comércio do vinho do Porto, já que a sua economia assume funções que vão muito além do espaço local.

A política econômica de organização do espaço encontra-se atrelada a um padrão institucional implantado e alterado em vários momentos, para ajustar-se e equilibrar-se às novas realidades. Nesse contexto, há vários acordos, tratados, instituições formais e organizações que constituem elementos fundamentais para operacionalização da produção e comércio do vinho do Porto. 
Três municípios destacam-se com organizações na estruturação atual da região: Vila Real, com a Universidade de Trás-os-Montes e Alto Douro (UTAD), a cultura e o Instituto dos vinhos do Porto e Douro (IVDP); Peso da Régua, com a Casa do Douro e a expansão do turismo; e Lamego, onde há especial vigor na formação em hotelaria, na produção de espumantes e no fumeiro. Este conjunto forma a "Douro Aliance" (fig. 1).

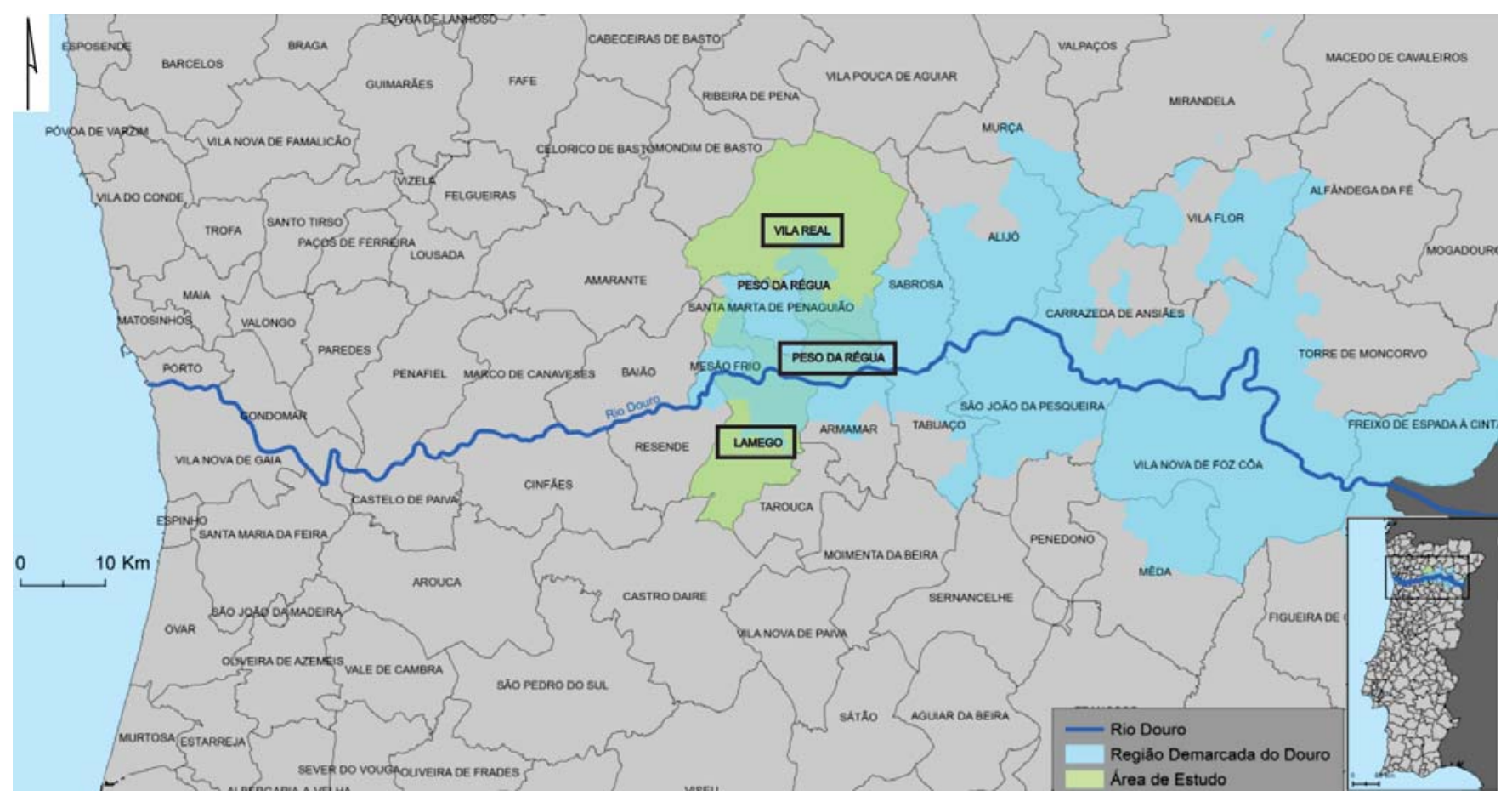

Fig. 1 - Região Demarcada do Douro (Douro Aliance: Vila Real, Régua e Lamego).

Figura a cores disponível online.

Fig. 1 - Douro Demarcated Region (Douro Aliance: Vila Real, Régua e Lamego). Colour figure available online.

Fonte: Carta Administrativa de Portugal - CAOP (2015)

Estes três espaços reuniam 95672 habitantes, 46\% da população da região do Douro em 2011, assim distribuídos: Vila Real (25\%), Peso da Régua (8\%) e Lamego (13\%).

$\mathrm{Na}$ tentativa de estabelecer um entendimento entre as relações urbano-rurais na RDD, defendemos que o essencial está associado ao vinho, e não é possível dissociá-lo do território nem das cidades mais importantes, pois neles estão o Estado, outros atores públicos e o setor privado. A produção de vinho é local, mas a representatividade econômica extrapola essa dimensão e alcança a cidade do Porto e a de Vila Nova de Gaia.

A partir desta configuração, o objetivo aqui é analisar e entender a Região do Douro, produtora de vinhos, na perspectiva da governança, e dos agentes, bem como a (des) articulação de poderes que organizam o espaço. O período de análise é o século passado e os primeiros 15 anos do século atual, embora em algumas ocasiões voltemos um pouco 
mais no tempo para garantir a compreensão do processo. As questões que norteiam este trabalho são: 1) Em que medida houve alteração no papel do Estado?; 2) Quem são os agentes envolvidos no processo de governação/ governança no Douro?; 3) Em que medida as políticas e fundos de financiamento da União Europeia (UE) tiveram impacto no negócio de vinhos do Porto?

Com a questão teórica aprofunda-se o entendimento sobre a governança e a abordagem institucionalista, procurando se estabelecer diálogo entre elas, por meio das políticas públicas portuguesas específicas para o setor de vitivinicultura.

Para responder às questões colocadas, foi feita uma pesquisa documental no Instituto Nacional de Estatística (INE), no Instituto dos Vinhos do Douro e Porto (IVDP) e em cooperativas ligadas ao setor, bem como um conjunto de entrevistas a especialistas no Douro. Paralelamente, foi feita a revisão da literatura para a construção do quadro teórico.

Este trabalho está inserido numa análise crítica sobre o método histórico e dialético, que consiste em investigar acontecimentos, processos e instituições do passado, para verificar sua influência na sociedade atual. É pertinente lembrar que este artigo não tem a pretensão de contemplar todos os elementos que compõem e envolvem a realidade do Douro, e sim promover um olhar, mais um olhar, desse universo.

$\mathrm{O}$ artigo encontra-se organizado em quatro secções. A primeira aborda o Douro. A segunda expõe o marco teórico voltado para a governança e a dimensão institucional, de forma combinada, no contexto da Região Demarcada do Douro. A terceira analisa o Douro, sob a ótica do processo de governança. Por último, apresentam-se as considerações finais.

\section{GOVERNANÇA E INSTITUIÇÕES}

Apesar da existência de textos e teorias sobre a abordagem institucionalista e a governança trabalhadas de forma individualizada, tais como Martin (2000); Amin (2000); Fernandes e Chamusca (2009); Ferrão (2013); Chamusca (2013), entre outros, optamos por pensá-las aqui de forma combinada, discutindo conceitos como instituições e governança, no contexto de políticas e regulamentos implementados na Região do Douro, produtora de vinhos. Tais conceitos serão trabalhados, procurando-se, sempre que possível, ilustrá-los com exemplos.

Lacaze (1995, p. 21) afirma que, "além de se tornar uma política pública definida como tal, o ordenamento do território é um campo de forças onde, por um lado, há o poder centralizador dos estados, desejosos de impor um modelo de organização fundamentado no controle e no domínio, e, por outro, há o jogo complexo das iniciativas individuais e das forças econômicas, no qual as cidades desempenham papel principal".

Para Veblen (1965), a abordagem institucionalista apresenta uma visão histórica e evolutiva do processo de transformação econômica e social, e adota como ponto de partida da análise a sociedade com seus comportamentos. Essa teoria atribui grande impor- 
tância ao poder e ressalta o papel do Estado, destacando os sistemas ideológicos e de poder expressos nas esferas política e governamental, como variáveis que determinam a evolução do processo de desenvolvimento.

Falar de jogo de poder remete para a questão das instituições, posto que elas são criadas e posteriormente modificadas pela sociedade para organizar a vida em comum. Portanto, se existe uma política de planejamento do território, ela precisa estar fundamentada em instituições formais. Ayres (Mehier, 1995, considera que as instituições constituem um elemento a partir do qual os sistemas econômicos podem ser analisados, além de serem essenciais para a concretização de determinada política pública.

Relativamente à compreensão das instituições e seu papel, importa considerar que North (1993, p. 7) as define "como um conjunto de regras, procedimentos de aceitação e normas de comportamentos morais e éticos, criados para restringir o comportamento dos indivíduos. As instituições políticas e econômicas formam a estrutura de incentivos de uma sociedade, portanto, são fatores fundamentais ao desempenho econômico".

Ampliando o conceito de instituição econômica, North (1993, p. 7) aponta "a existência de regras formais e informais. A última torna-se relevante, uma vez que são consideradas como informações passadas de geração em geração, constituindo parte da cultura de um grupo".

Williamson (1993) e North (1993) concordam com a existência de interdependência e complementaridade, posto que as instituições informais influenciam as instituições formais. Por outras palavras, as instituições misturam-se, combinam-se e contradizem-se em alguns momentos, de acordo com um processo dinâmico que se materializa no espaço.

De modo geral, as instituições formais mudam em menor espaço de tempo e precisam da ação coerciva do Estado para a mudança, enquanto as instituições informais dependem da vontade, da crença de seus seguidores - a sociedade. As crenças não mudam em espaços de tempo curtos, ao contrário, demoram para se consolidar. Enfim, as instituições (formais e informais) têm o papel de restringir o processo de decisão de cada agente (Alston, 1999).

A perspectiva institucional na geografia é evidenciada por Martin (2000) quando distingue os conceitos de ambiente institucional e arranjo institucional. $\mathrm{O}$ conceito de ambiente institucional, compreendido como sistema formal e informal de normas e convenções, atua como suporte para o aproveitamento de recursos específicos no território, permitindo evidenciar mecanismos de coordenação.

A noção de arranjo institucional, por sua vez, denota uma forma particular de organização, como as agências reguladoras, as companhias de desenvolvimento regional, os consórcios municipais etc., que apoiam a formação de um território. O interesse por esses conceitos reside no entendimento de como as organizações econômicas, políticas e sociais surgem, funcionam, evoluem e criam arranjos influenciados pelo ambiente institucional. Torna-se clara a grande influência dos trabalhos de North (1993) e Williamson (1993) na abordagem institucional da geografia. 
North estende sua análise às organizações que, assim como as instituições, proveem estrutura para interação humana, mas com elas não se confundem. Segundo ele:

“(...) as organizações se compõem de grupos de indivíduos unidos por um propósito comum. As organizações são políticas (partidos políticos, congressos, agências reguladoras), econômicas (empresas, sindicatos, cooperativas), sociais (igrejas, clubes, associações) e educativas (escolas, universidades)." (North, 1993, p. 7-8).

Partindo dessa concepção, North (1993) distingue instituições e organizações: as primeiras como as regras do jogo; e as últimas como os jogadores. Posteriormente, ele afirma que as instituições determinam as organizações e vice-versa. Em outras palavras, quando ocorrem alterações, é gerada, temporariamente, uma situação de desequilíbrio, que leva os agentes a repensar novas organizações e instituições que estejam adaptadas à situação presente. As organizações políticas ou econômicas competem para transformar as instituições da maneira que mais atenda a seus interesses.

Há um diálogo entre a realidade institucional do Douro vinhateiro e o entendimento institucionalista A título de exemplo, a visão do meio sob a organização produtiva do Douro vinhateiro teve e tem consequências importantes na própria indução da Região Demarcada do Douro, por meio de distintas organizações oficiais, como a Comissão de Viticultura da Região Duriense (criada em 1907 e extinta em 1932), a Associação dos Exportadores do Vinho do Porto, a Casa do Douro (1932), a Associação das Empresas de Vinho do Porto (constituída em 1975), o Instituto dos Vinhos do Douro e do Porto, I. P., adiante designado por IVDP', e a Federação Renovação Douro, que, de certa forma, atuam sob uma concepção regional.

As organizações citadas constituem elementos fundamentais deste Estado na aplicação e cumprimento da lei no processo de gestão do território. Apropriando-se do pensamento de Marx e Veblen, segundo Roll (1962), as várias organizações reforçam o processo de mudança e constroem o sistema estatal, baseando-se num conflito entre forças. Tal é evidente no Douro, como testemunha Pereira (2015), quando refere que num dos polos estão os pequenos produtores e, no outro, os comerciantes/ exportadores.

Tentando estabelecer uma relação entre as instituições e a governança na região do Douro, entendemos que no essencial esta relação está associada ao vinho, e não é possível dissociar nada do território nem das cidades mais importantes da região, pois nela e nelas se encontra o Estado e diferentes stakeholders dos setores público e privado. Deste modo, entende-se como essencial considerar as instituições como organizadoras do processo, posto que, em vários momentos, as pressões entre o setor comercial e o setor produtivo conduziram o Estado a estabelecer novo arranjo institucional para atender às demandas pertinentes do momento.

A mudança no arranjo institucional encontra-se intrinsecamente ligada às reflexões de ordem econômica e política envolvidas, como sustenta Lacaze (1995), para quem a organização dos poderes públicos e a ação econômica concentram o essencial dos meios de ação utilizáveis. 
Neste sentido, é possível estabelecer o diálogo com a governança, que "é uma nova forma de governar, um "novo modelo de gestão" do território para erradicar a pobreza e promover o desenvolvimento, como sublinhou Kofi Annan (1998, p. 2) em discurso."

Ao se falar em governança importa distinguir este conceito de governação. Na governação, está posto o tradicional governo, um modelo com o Estado no centro, seguindo uma lógica hierárquica. No modelo de governança existe uma tríade formada pelo Estado, a sociedade civil e o setor privado, em que o Estado recua em seu papel de decisor, abrindo espaço para a participação ativa dos outros agentes, mas mantendo um papel importante na mediação, em vários entendimentos, e garantindo a legitimidade das ações.

Segundo o Livro Branco da Governança Europeia (2001), são cinco os princípios da boa governança. O primeiro diz respeito à abertura, transparência e comunicação ampla da informação com linguagem acessível. A partir da divulgação, há a possibilidade de promover a participação da sociedade civil - segundo princípio -, e a qualidade das políticas depende dessa participação, entre concepção e execução, que favorecerá a eficácia das ações e a confiança no processo.

O terceiro princípio é o da responsabilização. A partir do momento em que há a participação, existe, simultaneamente, a responsabilização. Para isso, torna-se necessário definir, de forma clara, as atribuições para os poderes legislativo e executivo, considerando-se que a governança não é um fim em si mesma, mas um processo dinâmico e flexível. Neste percurso, conforme Bock (2006,), se todas as etapas acontecerem de forma satisfatória, mesmo sabendo da diversidade existente, haverá a eficácia - quarto princípio - do novo modelo de gestão. Mas, para isso, faz-se necessária uma consulta mais eficaz e transparente (Comisão das Comunidades Europeias, 2001) no centro da definição das políticas, sem desprezar as experiências do passado.

Em todo o processo, as políticas deverão estar fundamentadas em objetivos claros, ser eficazes e oportunas, dar respostas às necessidades do momento. Para Ferrão (2015), melhores práticas, legislação mais adequada e instituições mais capacitadas tornarão, certamente, as políticas mais eficazes.

Finalmente, há a coerência, como quinto princípio. Neste ponto, exige-se a coerência das políticas e liderança política para agir com a diversidade. Os princípios são importantes e devem ser postos em prática de forma conjunta, mas, para isso, é necessária uma cultura reforçada de consulta e diálogo.

Ampliando o entendimento de governança territorial, Carmo (2014, p. 42) diz "ser um conceito amplo e encontrar-se num campo particular: o território, que é um objeto complexo, relativamente ao qual há uma multiplicidade de atores". No caso específico do Douro e mesmo apenas em relação ao vinho do Porto, toda essa particularidade encontra-se presente. Lá estão o Estado, os pequenos produtores, representados pela Casa do Douro, a Associação de Exportadores de Vinho do Porto e, hoje, a União Europeia.

A sociedade e as instituições não são estáticas. No início do século XXI, vários autores, como Ascher (2001) e Jouve (2005,) sublinharam a ideia de que a sociedade contemporânea se transforma rapidamente, colocando novos desafios à governação dos territórios e obrigando a repensar modelos e estratégias de organização política, econômica e social. 
Aprofundando esse raciocínio, Fernandes (2009) e Chamusca (2013) apontam que a questão estrutural da governação está na estabilidade e na eficiência institucional, e se relaciona com o respeito às leis, com as estruturas deliberativas e com o equilíbrio entre as reivindicações da sociedade. Carmo (2014) vê a capacitação institucional e social como um dos aspectos fundamentais do processo de governança. Seguindo o entendimento do Livro Branco da Governança Europeia, Ferrão (2013 e 2015) coloca a participação pública como necessária, não apenas em momentos predefinidos, mas em todo o ciclo de política, considerando para o efeito a necessidade da existência de dispositivos institucionais que a favoreçam.

\section{GOVERNANÇA NO DOURO}

É possível observar um padrão institucional na Região Demarcada do Douro, no que tange ao uso do solo agrícola e à organização da produção. Dois usos refletem de modo claro esse padrão: o cultivo da vinha e a produção do vinho. Pereira (2008), afirma que na longa história da Região Demarcada do Douro e do sistema de regulação da produção e do comércio dos seus vinhos, determinada pelo alvará régio de 10 de setembro de 1756, começaram a ser tomadas as primeiras medidas legislativas, visando organizar e controlar a produção e o comércio de alguns dos vinhos mais prestigiados, no sentido de proteger a sua qualidade e reputação.

Para viabilizar o uso e o controle, existem organizações formais com uma lógica de atuação diferenciada, embora haja interdependência entre elas, uma vez "que não se pode compreender o território considerando elementos isoladamente, fora dos fenômenos circundantes" (Stalin, citado em Lakatos \& Marconi, 2000, p. 84).

Nesse caso, portanto, as instituições e regulamentações são elementos comuns à construção política e econômica de organização do espaço e controle da produção de vinho, pois possibilitam sua inserção e continuidade na economia global.

\section{Tradição e mudança}

Para analisar a governança na região do Douro, faz-se necessário expor como era estruturado o negócio do vinho para, em seguida, mostrar a situação atual. É preciso, pois, revisitar, regressar a tempos longos.

Adentrando a análise, chamar a atenção para a especificidade da RDD em seu processo histórico de plantio e produção vinho e, ao mesmo tempo, mostrar que as mudanças foram paulatinamente implantadas garantindo a competitividade e a tradição no saber fazer.

A representatividade da produção de vinho e de seu comércio em Portugal despontou, segundo Oliveira (1993, p. 223), como uma "poderosa coluna que sustentava a nação portuguesa no século XIX. Seu fortalecimento era contínuo, despertando o interesse de estudiosos em termos históricos, técnicos e do Estado, esse último preocupado em 
manter-se no controle". Martins (1988, p. 391) reitera que o vinho do Porto "constitui, sem dúvida, o mais importante produto da história econômica portuguesa dos últimos três séculos".

Vários arranjos institucionais (citados anteriormente) surgiram como instrumentos de governo, não apenas para melhorar o desempenho, mas também para adequá-lo às exigências de determinado contexto.

Houve problemas em relação à expansão das vinhas, nas exportações, adulterações, falsificações e sobreprodução. A sociedade exigia fiscalização, defesa dos interesses dos viticultores, defesa da denominação de origem e qualidade do produto. Para aprofundar a crise, estabeleceu-se uma fase de proliferação de pragas, que chegou a devastar cerca de $50 \%$ das áreas de cultivo. Diante de tantas intercorrências, Peixoto (2004) aponta o mês de julho de 1926 como um marco na regulação do vinho do Porto. Foram cinco decretos emitidos de forma incomum, que mudaram a face do setor.

Os produtores e exportadores foram enquadrados em grêmios ou associações específicas. Para o primeiro grupo criou-se a Federação na Casa do Douro, e os exportadores foram reunidos no Grêmio dos Exportadores do Vinho do Porto. Percebe-se, pois, a necessidade de novas políticas que emergiram de imperativos proclamados por movimentos sociais. Para intermediar, coordenar e fiscalizar as ações desse órgão, surgiu o Instituto de Vinhos do Porto (IVP), em 1933.

Nos anos 30 do século passado institucionalizou-se o benefício ${ }^{\text {ii }}$, mediante a criação de um método ${ }^{\text {iii }}$ para controlar a produção e a qualidade do vinho do Porto na Região Demarcada do Douro.

Como associação de capital público, o IVP tornou-se o centro de decisão e controle dos negócios do vinho, assumindo posição hegemônica durante algumas décadas, juntamente com o Instituto dos Vinhos do Douro e Porto (IVDP), tanto no controle da qualidade e quantidade dos vinhos do Porto quanto regulamentando o processo produtivo e as denominações de origem Douro e Porto.

Antes da revolução de $1974^{\text {iv }}$, vigorava o modelo corporativo, com organizações profissionais. O Grêmio dos Exportadores representava o comércio e, por outro lado, a Casa do Douro era o representante da produção. A articulação e a disciplina de cada setor competiam ao Estado, por meio do Instituto do Vinho do Porto. Depois da revolução no setor de vinho do Porto, o grêmio foi extinto e as empresas exportadoras associaram-se livremente e criaram a Associação dos Exportadores de Vinho do Porto, que depois passou a ser Associação das Empresas de Vinho do Porto, enquanto a Casa do Douro resistiu à extinção, porque naquela ocasião mantinha funções corporativas, tinha poderes de representação e mantinha poderes de tutela na denominação de origem, o que dificultou sua extinção.

Novas necessidades levaram a mudanças institucionais, e, usando o entendimento de North (1990), as instituições e organizações seriam mais fortes em sua adaptação à nova realidade. Segundo Ferrão (2015), as políticas públicas devem estimular a mudança e a transformação em função de determinados valores, desejos e finalidades, que precisam ser explicitados e debatidos. 
Nos anos 90 do século XX, o sistema instalado evoluiu para o Conselho Interprofissional, mudou-se o estatuto da Casa do Douro e criou-se, em 1995, uma Comissão Interprofissional da Região Demarcada do Douro (CIRDD), que incorporava representantes dos produtores e dos exportadores. Para Moreira (1998, p. 257), naquela ocasião, "a Casa do Douro deixou de ter poder para regulamentar em matéria de vinhos do Portov, mas manteve as tarefas de repartição dos benefícios e de intervenção no controle e fornecimento de aguardentes".

Neste século persistem alguns problemas na Região Demarcada do Douro, que levou o Estado a decretar, em novembro de 2003, uma nova reforma institucional, com a fusão do Conselho Interprofissional e o Instituto do Vinho do Porto, no Instituto dos Vinhos do Douro e Porto.

A Casa do Douro, principal representante dos pequenos produtores, vivenciou uma crise interna, com uma asfixia financeira que se arrastou por pelo menos duas décadas. Esse facto, inevitavelmente, enfraqueceu-a, levando o Estado a intervir, e delegar suas atribuições ao IVDP. Soma-se a isso a falência do modelo corporativo, segundo afirma Pereira (2015), em entrevista.

A superação parcial dessa crise instalada veio em 2003, com a nova legislação que designou a tutela do vinho do Porto ao Instituto dos Vinhos do Porto (IVP), enquanto a tutela dos vinhos do Douro passou para a CIRDD, em colaboração com a Casa do Douro. Nesse período, criou-se o Instituto dos Vinhos do Douro e Porto (IVDP) ${ }^{\text {vi }}$, que agrega o IVP e a CIRDD, instituto diferente, de tipo interprofissional, embora o diretor seja nomeado pelo Estado.

Com o novo enquadramento legal a Casa do Douro perdeu poderes de regulação. Manteve-se como instituição de direito público, em vez de ter passado a instituição de direito privado e, por essa via, resolvido os problemas advindos do modelo anterior. Com o tempo a situação tornou-se insustentável e, em 2014, o Estado decidiu vender a instituição. Neste momento, o caso encontra-se em tribunal.

Percebem-se, pois, alterações ao longo do tempo. A emergência das políticas neoliberais acabará por vingar, segundo defendem os jornais regionais e os responsáveis pelas grandes firmas de vinho do Porto. Se isso ocorrer, seus representantes, que comandam o processo, posicionar-se-ão para anular a existência do benefício e deixar livre o funcionamento do mercado, seguindo as regras da União Europeia. É certo que a qualidade continuará a ser controlada, mas a produção não, tanto em termos quantitativos quanto em termos de distribuição do direito de produzir.

O que é que estas questões têm a ver com a governança? Segundo Pina (2015), em entrevista, os pequenos produtores não têm quem os represente. A Casa do Douro neste momento não existe. É certo que há uma série de associações que oficialmente os representariam, mas na prática isso não ocorre. O IVDP não os representa. O modelo de cooperativas não deu certo, e, por conta de resultados financeiros insuficientes, os associados se desvinculam delas.

Hoje, as grandes firmas são obrigadas a comprar as uvas dos pequenos produtores para atender à demanda. Se o benefício acabar, a partir daí cada firma produzirá a quantidade de vinho do Porto que achar pertinente. O que acontecerá com os pequenos produtores? 
Outro aspecto preocupante na RDD é o "mercado" de transferência de licença, o qual há anos se faz de forma contida (Pina, 2004). O controle rígido fez-se presente e ficou estabelecido que a ampliação dos vinhedos e sua legalização fossem feitas por

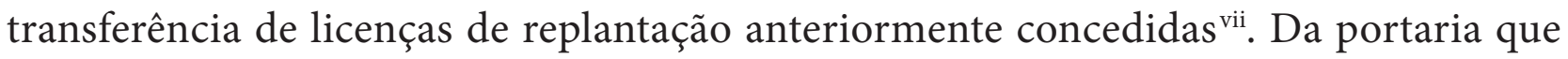
estabelece as regras ${ }^{\text {viii }}$ resultou um "mercado" de licenças, segundo Pina (2004), em que as grandes firmas apareciam como as principais interessadas, conduzindo à concentração, com algumas empresas adquirindo quintas, vinhedos, e fazendo a replantação de vinhas.

A cessão seria possível, posto que, na área, existia um número significativo de pequenos proprietários idosos com dificuldade de continuar no negócio, e os jovens, por sua vez, já haviam deixado a área em busca de novas oportunidades.

Todavia, a transferência de registros não seria regra geral quando, ao mesmo tempo, viticultores familiares, animados com apoios comunitários advindos do Banco Mundial e da União Europeia, aproveitaram a possibilidade de apoio em sucessivos programas, tais como o Programa de Apoio à Reestruturação da Vinha (CEE 2239/86), o Programa Operacional de Reestruturação da Vinha e Melhorias das Estruturas Vitivinícolas e o Regime de Apoio à Reestruturação e Reconversão da Vinha Tradicional.

A Organização Comum do Mercado opera desde 2003 e, por meio do Regulamento (CE) n. ${ }^{\circ}$ 1493/99 do Conselho, de 17 de maio, ficou estabelecida a organização comum do mercado vitivinícola, revogado pelo Reg. (CE) n. ${ }^{\circ}$ 479/2008, com todas as possibilidades postas em prática para melhorar a qualidade e produtividade, num desafio para aumentar a competitividade global.

Neste sentido, vários autores concordam, dentre eles Pina (2004; 2015), ser nítida a inserção da classe empresarial, capitalizada e tecnicamente preparada nos espaços mais privilegiados, com vinhedos ampliados e requalificados para mecanização ${ }^{\text {ix }}$. Os dados do IVDP (2014) confirmam a lenta e contínua inserção da categoria dos exportadores na produção: em 2010, eram 242, passando a 259 em 2015. Em oposição, estão milhares de pequenos proprietários, com exploração familiar, em que a tradição e o empirismo têm raízes profundas. Isso nos leva a perceber a lenta transformação no campo para um quadro de desigualdade socioeconômica, confirmado por indicadores do IVDP, acima citados.

De acordo com os dados do IVDP (2014), a Região Demarcada do Douro possui 23464 viticultores, totalizando 43 805ha, distribuídos entre várias categorias. Os produtores com até 1 ha são 15114 e ocupam uma área de 5726 ha. No outro extremo, estão os que operam acima de $20 \mathrm{ha}$, representados por apenas 259 produtores, que ocupam uma área de 11 168ha, ou seja, quase o dobro do grupo anterior. Para melhor visualização da realidade em questão, às grandes propriedades representam apenas $1 \%$ do total de exploradores, detendo $25 \%$ da área total. (fig. 2) Enquanto isto, 64\% dos exploradores ocupam apenas 135 ha da área. Revela-se concentração fundiária, com um pequeno número de proprietários explorando uma enorme porção de terras. Em entrevista, pode saber-se que 32 quintas que ocupam uma área de 2000 ha pertencem a apenas a um grupo, e 600ha de vinha pertencem a outro grupo. 


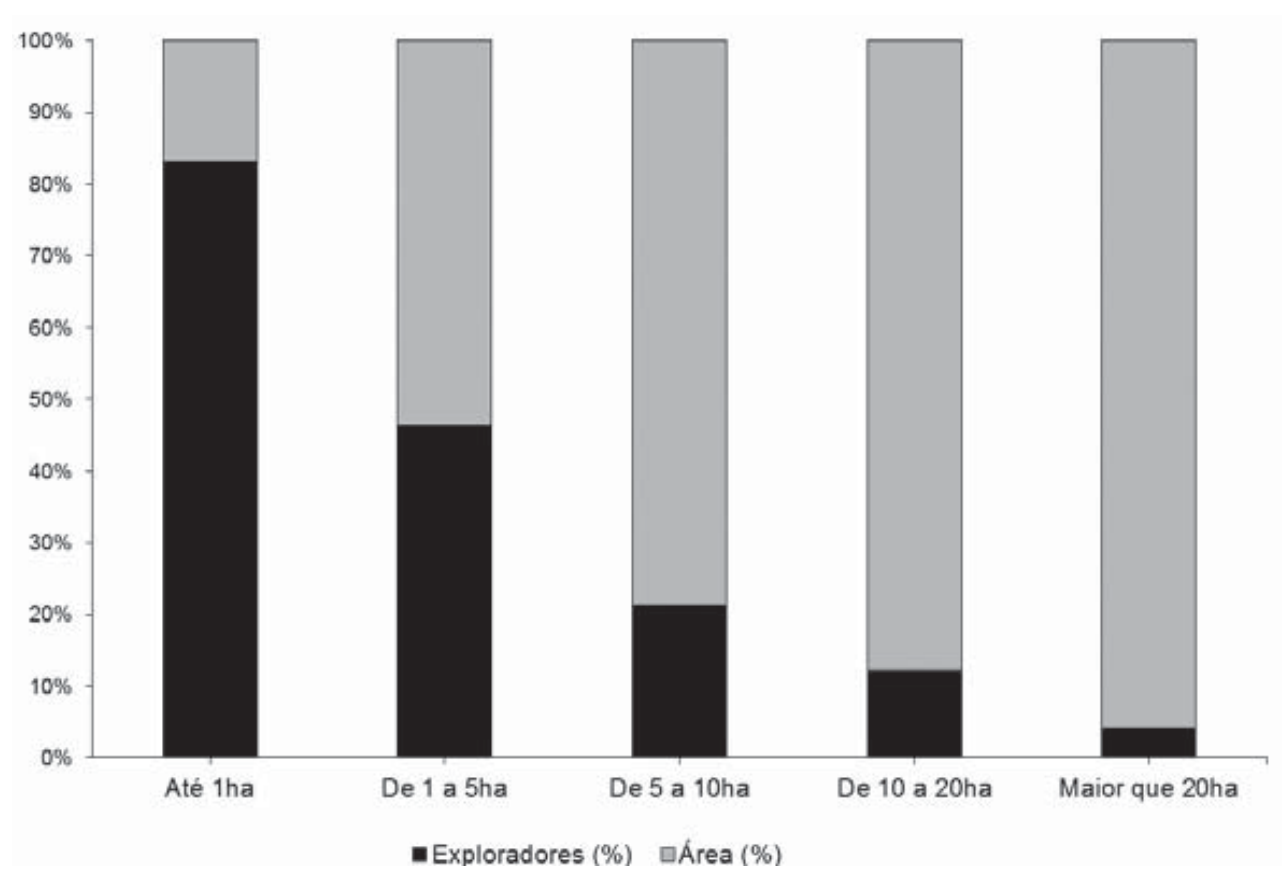

Fig. 2 - Exploradores por Área (\%). Região Demarcada do Douro, 2014.

Fig. 2 - Explorers by Area (\%). Douro Demarcated Region, 2014.

Fonte: Adaptado de IVDP (2014)

A expansão de grupos fortes e o apoio dado pelo Estado podem remeter a outra região do Nordeste brasileiro, a Zona da Mata, e alcançar o senhor de engenho de tempos longínquos, envolvido com a monocultura da cana-de-açúcar. Este ator, mais adiante, tornou-se usineiro e, ao mesmo tempo, político, enfim, dominante, usufruindo de subsídios, incentivos e benefícios do Estado, e hoje seus descendentes são políticos e empresários, a exemplo do que ocorre no Complexo Industrial e Portuário de Suape (Domingues, 2015).

Diante de conjunturas que levam à mudança institucional percebe-se que, nas negociações e nos acordos, estão os três elementos: o Estado, o pequeno produtor e o exportador. O jogo de poder é evidente, com os grupos dominantes a escolher seus sucessores e a influenciar a criação de instituições que defendam seus interesses, como afirmavam Veblen (1965) e North $(1981 ; 1990)$.

Quando comparamos a região portuguesa com a estrutura fundiária brasileira - historicamente desigual, segundo indicadores do Instituto Brasileiro de Geografia e Estatística (IBGE), ${ }^{\mathrm{x}}$ os quais apontam para uma enorme desigualdade na distribuição de terras, vemos situações semelhantes. No caso do Brasil, essa desigualdade leva a conflitos pela posse da terra, resultando, algumas vezes, em mortes. Então, questiona-se: esse seria um problema de países em desenvolvimento que adotaram o modelo do colonizador (monocultura e grande propriedade)? Como se explica a existência de concentração fundiária hoje em Portugal, "país desenvolvido"?

Apesar da desigualdade existente, não há pobreza de facto, tratando-se da RDD. Como vivem as pessoas que estão na base da economia do vinho? No Douro, consegue-se garantir um padrão de vida satisfatório a qualquer produtor que tenha 3ha e uma coordenação de ajuda (em termos de mão de obra) entre os membros da família e comuni- 
dade. Os mais jovens têm formação e trabalham em serviços nas cidades próximas, e, conjugando o rendimento formal com os ganhos do vinho, asseguram bons níveis de qualidade de vida, apesar de a região ser das mais pobres de Portugal. Por outro lado, os idosos têm reformas e, acrescentando-se a elas os rendimentos oriundo do vinho, possuem uma vida sem maiores problemas. As necessidades não são prementes. No entanto, isso não invalida que novas políticas públicas tenham no centro de suas formulações melhores condições para o pequeno produtor, além da inserção dos vinhos no mercado global, por via de médias e grandes empresas.

\section{Agentes e (des)articulação de poderes}

Pode considerar-se que o sistema de gestão do vinho, no Douro, tem três níveis: local, regional e o de quem controla os mercados e as cadeias de abastecimento. O poder local, a municipalidade, as câmaras, são importantes e vivenciam concretamente o dia a dia do território, mas não têm influência direta no processo de governança do negócio do vinho como definidor de regulamentos. Percebe-se que o negócio do vinho acontece no nível local, mas sua importância econômica extrapola essa dimensão, alcança a cidade do Porto e a de Vila Nova de Gaia e até a economia nacional que por sua vez encontra-se atrelada aos regulamentos da União Europeia.

Na região, o Estado ainda é forte, dentre outras razões, por via de poderes desconcentrados do Estado, tutelados indiretamente pelos ministérios. São espaços de negociação em termos de orçamento, espaços de poder, embora nada ou pouco ligados à questão do vinho.

O controlo do mercado, pode abordar-se de duas formas. A primeira é de ordem prática, ou seja, do poder não apenas definido pela lei. Um setor fundamentalmente econômico, associado à produção e ao comércio, tem sua estrutura essencialmente definida pelo comércio e pelos mercados. Da mesma forma, os mercados comandam as conjunturas. É a "mão invisível". Existem também as "mãos visíveis" das grandes empresas, que se encontram não apenas no setor produtivo e no comércio, mas também dominam o mercado. Neste sentido, as empresas de distribuição de vinhos do Douro e Porto têm um peso forte, algumas são internacionais, outras desnacionalizadas, estas ultimas anteriormente de capital português, a exemplo da empresa Porto Cruz, que é francesa, e a Taylor, composta sobretudo por capitais ingleses, e tantas outras.

A segunda forma de controle diz respeito ao plano jurídico interno, os agentes do modelo que opera desde 2003 são o IVDP e o Conselho Interprofissional, composto por lavradores, viticultores, produtores e negociantes. É um conselho paritário, embora presidido pelo representante do Estado, que é o presidente do IVDP. As profissões escolhem seus representantes e o IVDP os nomeia. Teoricamente, por lei, é um conselho autorregulador e interprofissional. Para Moreira (1998), é evidente que a autorregulação profissional tem como limites a regulação legislativa e regulamentar do Estado. Reitera Pereira (2015) em entrevista ser certo que todos os procedimentos e direções do sistema pertencem ao IVDP, órgão de tutela estatal. 
Existem também aspectos conjunturais que promovem uma organização do sistema. O primeiro diz respeito ao Conselho Interprofissional, composto por representantes dos viticultores e do comércio. Aqui está posta uma diferença significativa quanto ao poder de influenciar e favorecer seus interesses. A representação do comércio é não apenas coesa, bem estruturada, mas também forte. Soma-se a isso o facto de que o comércio avançou em direção a fusões, à concentração, e pode-se afirmar que meia dúzia de empresas são bastante representativas e dominam o setor, com os exportadores a ter cada vez mais poder na produção.

Enquanto isso, o segundo grupo, o dos produtores, não é bem organizado, pois thes falta formação. Como resultado, a estrutura de representação não existe. A Casa do Douro desapareceu em 31 de dezembro de 2014 (Diário da República, 2014), e sem esta deixou de haver uma associação, uma estrutura representativa dos 30 a 40 mil viticultores profissionais. Existem associações diversas, mas sem representação forte, perdendo-se a organização dicotômica dos vinhos do Douro e do Porto, no plano jurídico.

Tal conjuntura leva à proximidade do grande capital privado com o Estado. É fácil a uma associação que representa a grande empresa, com argumentos bem fundamentados, tomar alguma decisão ou influenciar o Conselho Interprofissional e, assim, chegar ao IVDP. Por outro lado, os pequenos produtores mantêm-se desarticulados, numa situação de fragmentação que evidencia enfraquecimento. A sociedade local vivencia isso, segundo informações obtidas em pesquisa de campo. Para Pina (2015), se os pequenos se unissem, eles comandariam o processo.

A definição dos benefícios anuais é feita pelo Conselho Interprofissional. Para definição do processo, análises "fundamentadas" são feitas por técnicos que estimam o que as grandes empresas exportadoras preveem exportar e a quantidade para cada produtor. $\mathrm{O}$ conselho delibera em reuniões formais. Essas reuniões ocorrem todos os anos entre julho e agosto, e a decisão chega aos produtores por meio do IVDP.

$\mathrm{Na}$ escala macro, em termos da legislação internacional de vinhos, sua tutela e representação competem ao Estado nacional, que pode delegar representações.

Existe outro agente no processo de gestão: a União Europeia. Seu papel no negócio do vinho do Douro se dá por meio da Política Agrícola Comum (PAC), que se organiza em duas fases. A primeira, já consolidada, tinha sua atenção para os países do Norte (mais fortalecidos), com a política do leite, carne e cereais. Posteriormente, voltou a atenção para os países do Sul, mas de forma secundária, com menos apoio a culturas preteridas. É um processo relativamente recente que, para Ferrão (2016), não tem como sentido o ordenamento do território, mas termina resultando grande efeito na organização do espaço e na compreensão da paisagem rural.

No caso específico, do negócio do vinho do Douro, a política agrícola europeia volta-se para resolver a questão do excedente de vinho existente no mercado. Isso ocorre mediante acordo possível com normatização dos preços dos vinhos para transformar o vinho excedente em aguardente vinícola a um custo adicional, que seria subsidiado. A Itália, a Espanha e a França aprovaram o uso dos subsídios europeus, todavia, essa política não foi implementada em Portugal. ara os grupos portugueses, mesmo com subsí- 
dios, tal política não seria rentável, posto que deixariam de pagar 150 euros a pipa para pagar 500 euros por ela. Por outro lado, numa escala maior, resolvia-se o problema da produção excedente de vinhos, transformando-a em aguardente. Entende-se que no modo capitalista de produção as grandes firmas manipulam e controlam o que lhes é conveniente. São algumas das estratégias usadas para se manter no mercado com vantagens competitivas.

Entendemos, pois, que a União Europeia não tem influência direta, mas tem força, à medida que as normas nacionais têm de se adequar às normas da União Europeia. É evidente que os tratados são respeitados, sobretudo a relação entre os mercados. Numa escala macro, existe a PAC, desmembrada em outros programas, como o Plano de Desenvolvimento Rural e o Programa Vitis, estratégico para os vinhos.

Toda a legislação que promova alterações profundas tem de ser submetida às leis nacionais, ou melhor, a legislação portuguesa precisa se submeter àquela da União Europeia. Por exemplo, a evolução da Casa do Douro, de certa maneira, é determinada pela União Europeia. Essa instituição pretendia assumir funções de comércio, o que foi vetado, pois um órgão de tutela corporativa não pode assumir função de regulador e, ao mesmo tempo, função de ator econômico.

Neste contexto, como se pode interpretar a alteração no papel do Estado? A transformação na Casa do Douro deve ser associada ao modelo de política que houve nos anos 90 do século passado. Foi a passagem da tutela do Estado e das profissões de um modelo corporativo (extinto em 1974, mas na realidade apenas parcialmente) para o modelo interprofissional. O Estado não abdica de sua posição de regulador, mas articula a posição de autorregulação para quem está no setor. Há, evidentemente, aspectos ligados à liberalização, mas seria uma explicação simples, que não condiz com as particularidades do setor.

Há outros aspectos que o modelo de autorregulação não controla totalmente, em especial no que diz respeito aos interesses dos pequenos produtores. O Estado tem de representar os interesses coletivos, entretanto, delega para que se autorregulem. Para Moreira (1998), a autorregulação só opera no espaço deixado livre pela regulação estatal. É pertinente lembrar que, no seio desses órgãos existem interesses privados reivindicados por grupos fortes. O diretor do IVDP é quem convoca e preside as reuniões interprofissionais. $\mathrm{Na}$ análise da governança, não é possível desligar a governança institucional da governança econômica e do mercado.

A cadeia de abastecimento dos vinhos do Douro vem desde as vinhas até os mercados, e, neste contexto, há uma luta pelo poder por meio do estabelecimento do preço, da quantidade a ser produzida, do escoamento dos excedentes ou não. E mais: Onde se encontram os verdadeiros centros de decisão? Em Nova York, na sede de uma grande empresa de distribuição internacional. E, se são eles que dominam, podem criar mercados conjunturais imateriais, como, por exemplo, o valor de um vinho algumas vezes definido por uma revista internacional. Nesse mesmo contexto, pode ser visto o papel da União Europeia, em larga medida dependente de quem determina as taxas de juros, o valor dos spreads e as políticas de inflação ou deflação. 
Entretanto, percebe-se a autonomia do Estado Português em relação à denominação de origem do vinho, mas Portugal tem de se enquadrar nas diretrizes da União Europeia, fazendo os devidos ajustes na legislação. Isto é uma das exigências básicas para se manter no bloco. A título de exemplo, no que diz respeito aos investimentos futuros em Portugal a União Europeia aponta que não haverá investimento para a infraestrutura viária, pois segundo o entendimento de Bruxelas a prioridade, no momento, será para a cultura.

Exemplificando a prática integrada à teoria, podemos fazer um paralelo tanto com as ideias da abordagem institucionalista como com o modelo de governança. No primeiro caso, Commons (Bazzoli \& Dutraive, 1995) coloca no centro da teoria econômica a análise dos processos de produção de regras de comportamento pela ação coletiva, a fim de compreender as atividades econômicas e o capitalismo. Em Commons, as instituições tornam-se, assim, sedes de uma rede de transações reguladas, em que o indivíduo é, ao mesmo tempo, subordinado e ator.

No segundo caso, o modelo de governança é entendido como uma forma nova de planejar e gerir, com o envolvimento de outros atores, além do Estado. Teoricamente, o setor privado e a sociedade civil são inseridos no contexto, dialogando em busca da melhor estratégia. No entanto, a participação só ganha verdadeira relevância, quando se associa à possibilidade ou capacidade de decidir, segundo Ferrão (2015).

Nesta equação, encontram-se três elementos: o Estado, o setor privado e a sociedade civil. Na disputa, encontram-se dois elementos: o Estado, em seu papel de mediação e institucionalização por meio das leis; e o setor privado, representado por dois segmentos que disputam no campo de força: os pequenos produtores e a associação dos exportadores. Neste sentido, em termos de equilíbrio na participação, o processo de governança não ocorre de forma plena, embora não esteja apenas esta variável em questão, pois, se acontecem melhores práticas e instituições mais adequadas, políticas públicas específicas podem ser eficazes.

\section{CONSIDERAÇÕES FINAIS}

É possível observar uma aproximação entre dispositivos institucionais e a organização do espaço na Região Demarcada do Douro. Essa percepção ocorre ao se concentrar a atenção na adoção de estratégias, normas e procedimentos que conferem força política e econômica a determinadas organizações envolvidas com o negócio do vinho. Para fundamentar essa ideia e esclarecê-la, dividimos o trabalho em alguns pontos, embora saibamos que essa divisão na prática não existe, porque, quando um segmento é alterado, os outros envolvidos também o são. Eles se contradizem em determinados momentos, complementam-se em outros, enfim, são inseparáveis.

O primeiro ponto prende-se com a regulamentação. O negócio do vinho é profundamente regulamentado em Portugal. O Estado sempre esteve presente no controle e na organização da região, mediante políticas territoriais explícitas, pensadas para aquele território. Mais recentemente delibera a autorregulação aos próprios interessados. Seria 
uma forma de descentralização territorial, mas é sua a última palavra na criação de instituições e reorganização do uso do espaço. Percebe-se, pois, que houve alteração no papel do Estado, embora ele não abdique de sua posição de regulador.

A nível europeu existe a regulamentação comunitária. Nesse caso, o que é pensado em Portugal a respeito da política de vinhos ou política agrícola está alinhado com as diretrizes gerais da União Europeia. Deste modo, mesmo não assumindo interferência direta na política de vinhos, a UE encontra-se presente numa posição superior em termos de diretrizes gerais, mas não acima do Estado nacional.

Em termos de operacionalização do processo de governança estão o Estado e o setor privado. Em nosso entendimento, existe um jogo de forças, como em qualquer outra situação, e o vencedor, na instituição das leis e na formulação de políticas territoriais explícitas, é o grupo mais bem estruturado e com maior poder de barganha. No presente caso, o grupo dominante é o dos exportadores.

No que se refere ao comércio e à exportação, estes mantêm-se em situação confortável, mesmo com as oscilações de mercado, uma vez que seus representantes têm-se expandido para a área de cultivo e produção, comprando vinhedos e quintas.

Ainda neste contexto, podemos acrescentar outro ponto para reflexão, que diz respeito à questão da tradição e mudança. Existe a regulamentação do negócio do vinho, porém a modernização está presente, mesmo de forma lenta, no que se refere à troca das vinhas e ao processo de produção. Nessa dimensão, é essencial o papel da Universidade Trás-os-Montes e Alto Douro, desenvolvendo conhecimento para o melhoramento das castas e da qualidade do vinho e formando enólogos e outros especialistas que têm proporcionado enorme aumento da qualidade e aumento também do valor acrescentado.

A Região Demarcada do Douro é hoje viável em duas direções. Primeiramente, com a manutenção de sua paisagem, alcança o negócio de turismo, aumentando significativamente o número de visitantes de ano para ano e aumentando também, mas não tanto, o número e a qualidade de unidades de alojamento e restauração. Para sua viabilidade, encontra-se em vigor a regulamentação para preservação, qualificando-se com maior valoração. Pode ser visto como associado a este plano o papel do pequeno produtor, conservando a paisagem e a cultura que justificaram sua valoração.

A outra direção é aquela historicamente vivida pela região: da produção de vinho, sua manutenção no mercado internacional com produtos diferenciados, o vinho do Porto e o vinho de mesa, e da disputa histórica entre pequenos produtores e exportadores.

\section{AGRADECIMENTOS}

À Coordenação de Aperfeiçoamento de Pessoal de Nível Superior (CAPES), financiadora do Programa de Estágio Sênior na Universidade do Porto, Portugal.

Ao Professor José Alberto Rio Fernandes (FLUP, Porto, Portugal), meu supervisor, por possibilitar o processo de aprendizagem e o desenvolvimento deste trabalho de pesquisa. 


\section{REFERÊNCIAS BIBLIOGRÁFICAS}

Alston, L. J. (1999). A framework for understanding the New Institutional Economics. Illinois: University of Illinois.

Amin, A. (2000). Una perspectiva instituticionalista sobre el desarrollo económico regional [An Institutionalist Perspective on Regional Economic Development]. Cadernos do IPPUR, 14(2), 47-68.

Annan, K. (1998). Report of the Secretary-General on the work of the Organization. Chapter II. ONU.

Barcelos, R. M. (2003). A Nova Economia Institucional: Teoria e Aplicações [The New Institutional Economy: Theory and Applications]. Brasília: UnB/ IH/ECO.

Bazzoli, L., \& Dutraive, V. (1995). Léconomie de l'action colletive de John Roger Commons [The Economics of Collective Action by John Roger Commons]. In V. Dutraive (Coord.), L'Économie Institutionnaliste: les fondateurs (pp. 29-45). Paris: Economica.

Bock, S. (2006). "City 2030" - 21 cities in quest of the future: New forms of urban and regional governance. European Planning Studies, 14(3), 321-334.

Carmo, F. (2014). Planos Regionais de Ordenamento do Território e governança territorial: do discurso às evidências da prática [Regional Plans for Spatial Planning and territorial governance: from discourse to evidence of practice]. GOT - Revista de Geografia e Ordenamento do Território, 5, 41-65.

Chamusca, P. (2013). Novos desafios e objetivos de governação territorial: discutindo a reorganização do Estado e a conceptualização da governança como modelo de gestão dos territórios [New challenges and objectives of territorial governance: discussing the reorganization of the State and the conceptualization of governance as a model of territorial management]. GOT Revista de Geografia e Ordenamento do Território, 4, 31-55.

Comissão das Comunidades Europeias (2001). Governança Europeia. Um Livro Branco [European Governance. A White Paper]. Bruxelas: Comissão das Comunidades Europeias. Retrieved from: http://www.laicidade.org/wp-content/uploads 12006/09/ue-governanca-2001.pdf

Domingues, R A. (2015). Ordenamento do Território no Complexo Portuário de Suape - Brasil [Territory
Planning at the Suape Port Complex - Brazil]. Anais do X Congresso da Geografia Portuguesa. Os valores da geografia, Lisboa.

Domingues, R. A. (2013). Instituições e o controle do espaço: um olhar da geografia [Institutions and the control of space: a look of geograph]. XIII Colóquio Internacional de Geocrítica. Retrieved from: http://www.ub.edu/geocrit/xiii-coloqprograma.htm

Fernandes, J. A. R., \& Chamusca, P. (2009). Governância, planeamento e estratégias de desenvolvimento territorial: reflexões a propósito da teoria e da prática [Governance, planning and territorial development strategies: reflections on theory and practice]. Inforgeo, 24, 27-43.

Ferrão, J. (2015). Políticas Territoriais Eficazes e Participadas [Effective and Participated Territorial Policies]. Instituto de Ciências Sociais, Universidade de Lisboa Animar-Dl. PT. Retrieved from: http://www.animar-dl.pt/comunicacao/pontode-vista/704-politicas-territoriais-eficazes-eparticipadas-joao-ferrao

Ferrão, J. (2013). Governança, Governo e Ordenamento do Território em Contextos Metropolitanos [Governance, Government and Spatial Planning in Metropolitan Contexts]. In A. Ferreira, J. Rua, G. J. Marafon, \& A. C. P. Silva (Org.), Metropolização do Espaço: Gestão Territorial e Relações Urbano-Rurais [Metropolization of Space: Territorial Management and Urban-Rural Relations] (pp. 255-281). Rio de Janeiro: Consequência.

Jouve, B. (2005). From government to urban governance in Western Europe: A critical analysis. Public Administration and Development, 4(25), 285-294.

Lakatos, E. M., \& Marconi, M. A. (2000). Metodologia científica [Scientific methodology]. 3a ed. São Paulo: Atlas.

Lacaze J. P. (1995). O ordenamento do território [Territorial planning]. Lisboa: Instituto Piaget.

Lei $n^{\circ}$ 97/2012 (2012). Ministério da Agricultura, do Mar, do Ambiente e do Ordenamento do Território [Ministry of Agriculture, the Sea, Environment and Spatial Planning]. Aprova a orgânica do Instituto dos Vinhos do Douro e do Porto, I. P. Retrieved from: http://legislacaoportuguesa. com/decreto-lei-n-o-972012-d-r-n-o-80-serie-ide-2012-04-23/ 
Lavrador, A., \& Rocha, J. (2010). A região demarcada dos vinhos verdes, uma paisagem e uma identidade ameaçadas. paisagem, património e desenvolvimento [The demarcated region of green wines, an endangered landscape and identity. Landscape, heritage and development]. Actas do XII Colóquio Ibérico de Geografia. Porto: Faculdade de Letras, Universidade do Porto. Retrieved from: http://web.letras.up.pt/xiicig/comunicacoes/134.pdf

Martins, C. A. (1988). Os ciclos do vinho do Porto: ensaio de periodização [Port wine cycles: periodization test]. Análise Social, XXIV(100), 391-429.

Martin, R. (2000). Institutional approaches in economic geography. A companion to economic geography. London: BlackWell Publishers.

Marques, H. (1987). Região demarcada dos vinhos verdes [Green wine region]. Revista da Faculdade de Letras - Geografia, 1(3), 135-242.

Mehier, C. (1995). Les apports de Clarence Edwin Ayres: place et rôle de la tecnologie dans la dynamique économique [The contributions of Clarence Edwin Ayres: the role and role of technology in economic dynamic]. In V. Dutraive (Coord.), L'Économie Institutionaliste: les fondateurs [Institutional Economics: the founders] (pp. 61-75). Paris: Economica.

Ministério da Agricultura, do Desenvolvimento Rural e das Pescas (2015). Artigo 2. ${ }^{\circ}$ do Decreto-Lei n. ${ }^{\circ} 83 / 97$, de 9 de abril, alterado pelo Decreto-Lei n. ${ }^{\circ} 423 / 99$, de 21 de setembro; $n .^{\circ} 5$ do artigo $92 .^{\circ}$ do Regulamento (CE) n. ${ }^{\circ} 497 / 2008$, do Conselho, de 29 de abril. Retrieved from: https://www. ivdp.pt/pagina.asp? content $=$ destaque $\& \operatorname{cod}=200$

Moreira, V. (1998). O sistema regulatório do vinho do Porto (e dos demais vinhos do Douro) [The regulatory system for Port wine (and other Douro wines]. In V. Moreira (Ed.), O governo de Baco [The government of Bacchus] (pp. 225-283). Porto: Edições Afrontamento Lta.

North, D. C. (1993). Desempeño económico en el transcurso de los años [Economic performance over the year]. Conferencia de North en Estocolmo, Suecia, el 09 diciembre del 1993 al recibir el Premio Nobel de Ciencias Económicas. Retrieved from: www.eumed.net

North, D. C. (1990). Institutions, institutional change and economic performance. New York: Cambridge University Press.
North, D. C. (1981). Structure and change in economic history. New York: W.W. Norton.

Oliveira, A. (1993). O Douro país vinhateiro. Da produção ao comércio. Algumas considerações [The Douro wine country. From production to trade. Some considerations]. Revista de História, 12, 221-244.

Peixoto, F. (2004). Entreposto de Gaia. Um viveiro de conflitos. Douro [Warehouse of Gaia. A breeding ground for conflict. Douro]. Estudos \& documentos, 18(6), 57-88.

Pereira, G. M. (2008). Nos 250 anos da região demarcada do douro: da companhia pombalina à regulação interprofissional [In the 250 years of the demarcated region of Douro: from the Pombaline company to interprofessional regulation] In F. Sousa (Org.) A Companhia e as relações económicas de Portugal com o Brasil, a Inglaterra e a Rússia [The Company and Portugal's economic relations with Brazil, England and Russia] (pp. 175-185). Porto: Faculdade de Letras da Universidade do Porto.

Pina, M. H. M. (2004). A expansão e a reconversão vitícola na região demarcada do Douro - algumas problemáticas [The expansion and reconversion of vineyards in the demarcated region of the Douro]. Actas do V Congresso da Geografia Portuguesa, Associação Portuguesa de Geógrafos, Universidade do Minho, Guimarães (pp. 319-342).

Raffestin, C. (1993). Por uma geografia do poder [For a geography of power]. São Paulo: Ática.

Roll, E. (1962). História das doutrinas económicas [History of economic doctrines]. São Paulo: Nacional.

Rückert, A. A. (2007). A Política Nacional de Ordenamento Territorial, Brasil. Uma política territorial contemporânea em construção [The National Policy of Territorial Planning, Brazil. A contemporary territorial policy under construction]. Scripta Nova, Revista Electrónica de Geografía Y Ciencias Sociales, XI(245), 66.

Veblen, T. (2000). Sobre la naturaleza del capital [On the nature of capita]. Revista de Economía Institucional, 2, 197-216.

Veblen, T. (1965). A teoria da classe ociosa: um estudo econômico das instituições [The theory of the idle class: an economic study of institution]. São Paulo: Pioneira.

Williamson, O. E. (1993). Transactions cost economics and organization theory [Transactions cost economics and organization theory]. Berkeley: University of California. 
Diário da República (2014). Portugal. 1. a série, N. ${ }^{\circ}$ 199, 15 de outubro. Retrieved from: https://www. ivdp.pt/pt/docs/legislacao/410.pdf
Diário da República (2008). Portugal. 2. ${ }^{a}$ série - N. ${ }^{\circ} 102$ - 27 de maio de 2015. Retrieved from: https:// dre.pt/application/conteudo/67324020

i É um instituto público, integrado na administração indireta do Estado, de natureza interprofissional, nos termos do Decreto-Lei n. 97 (2012), de 23 de abril.

ii Benefício é a autorização que cada produtor recebe para produzir vinho do Porto.

iii A partir de 1940, a Casa do Douro começou a repartir o benefício de acordo com um método sofisticado de classificação idealizado pelo Eng. Álvaro Moreira da Fonseca.

iv O regime do Estado Novo, a mais antiga ditadura europeia, acabaria por ser deposto a 25 de abril de 1974. Informações disponíveis em: http://www.dw.com/pt/cronologia-1970-1974

v O regime regulatório do vinho do Porto é mais denso do que o dos demais vinhos de qualidade. Mais informações em Moreira (1998).

vi É um instituto público de natureza interprofissional, nos termos do Decreto-Lei n. ${ }^{\circ} 97$ (2012), de 23 de abril. O Instituto é integrado na administração indireta do Estado, dotado de autonomia administrativa e financeira e patrimônio próprio.

vii Segundo Pina (2014, p. 324), no ano 2000, as licenças chegaram a ser 'comercializadas' a 4000 contos/hectare.

viii Foi publicada a portaria que estabelece as regras de transferência de direitos de replantação entre explorações, os quais, transferidos para a Região Demarcada do Douro, não podem ser utilizados para o abrigo do disposto no artigo $2 .^{\circ}$ do Decreto-Lei n. ${ }^{\circ}$ 83/97, de 9 de abril, alterado pelo Decreto-Lei n. ${ }^{\circ}$ 423/99, de 21 de setembro, em que manda o governo, pelo Ministro da Agricultura, do Desenvolvimento Rural e das Pescas, o seguinte: $1 .^{\circ} \mathrm{O}$ disposto na presente portaria destina-se a fixar, para o território do continente, as regras complementares de aplicação do $n .^{\circ} 5$ do artigo 92. ${ }^{\circ}$ do Regulamento (CE) n. ${ }^{\circ}$ 497/2008, do Conselho, de 29 de abril, relativamente à transferência de direitos de replantação entre explorações (Diário da República, 2008).

ix Esse não é um processo geral, posto que alguns, dentre os melhores vinhos, são produzidos por métodos tradicionais, cuja colheita é feita durante a noite, mas algumas uvas são deixadas para colheita na noite seguinte. Tudo isso é em prol da qualidade e sofisticação do como fazer.

x Órgão do governo brasileiro encarregado do levantamento de dados do país. É semelhante ao INE. 